\title{
Case for diagnosis. Solitary violaceous nodule on the toe*
}

\author{
Katarina Kieselova ${ }^{1}$, Felicidade Santiago ${ }^{1}$, Cristina Amado $^{2}$, Martinha Henrique ${ }^{1}$
}

DOI: http:/ / dx.doi.org/10.1590/abd1806-4841.20187445

\section{CASE REPORT}

A 45-year-old man, otherwise healthy, presented to our department with an asymptomatic cutaneous lesion on the third toe of his left foot. The patient reported sudden appearance of the lesion two months ago, with no preceding trauma or insect bite in the area. On examination, the lesion was a $7 \mathrm{~mm}$ firm violaceous non-mobile nodule, with smooth surface and well-defined borders (Figure 1). General physical examination did not show any abnormalities. Dermoscopy under polarized light revealed homogenous pink coloration with superficial white scale on the lower half of the lesion (Figure 2). We proceeded to complete excision of the lesion, and histopathologic examination revealed a nodular dermal area consisting of multinucleated histiocytic cells with eosinophilic "ground glass" cytoplasm (Figure 3). Immunohistochemistry showed that these cells were positive for CD68 and vimentin and negative for S100 (Figure 4). An adjacent mononuclear inflammatory infiltrate was observed.

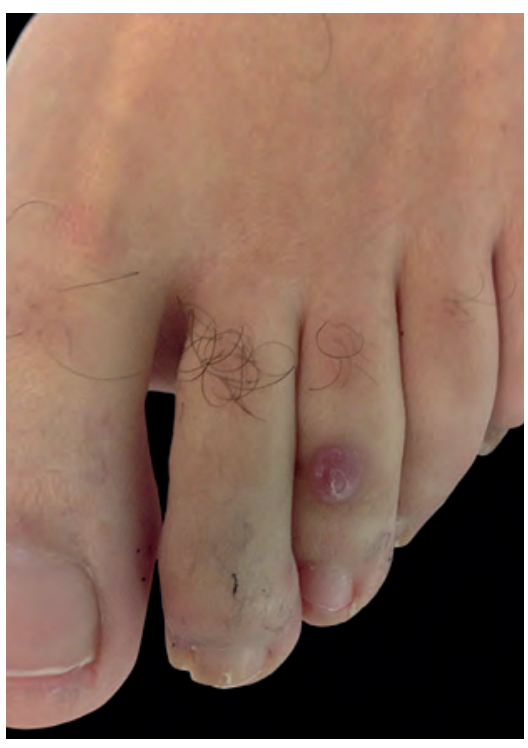

Figure 1: Violaceous nodule on the toe

\footnotetext{
Received 20 July 2017.

Accepted 15 December 2017.

* Work conducted at the Department of Dermatology, Centro Hospitalar de Leiria, Leiria, Portugal.

Financial support: None.

Conflict of interest: None.

Department of Dermatology, Centro Hospitalar de Leiria, Leiria, Portugal.

2. Department of Pathology, Centro Hospitalar de Leiria, Leiria, Portugal.

MAILING AdDREsS:

Katarina Kieselova

E-mail: katarinakieselova@gmail.com

C2018 by Anais Brasileiros de Dermatologia
} 


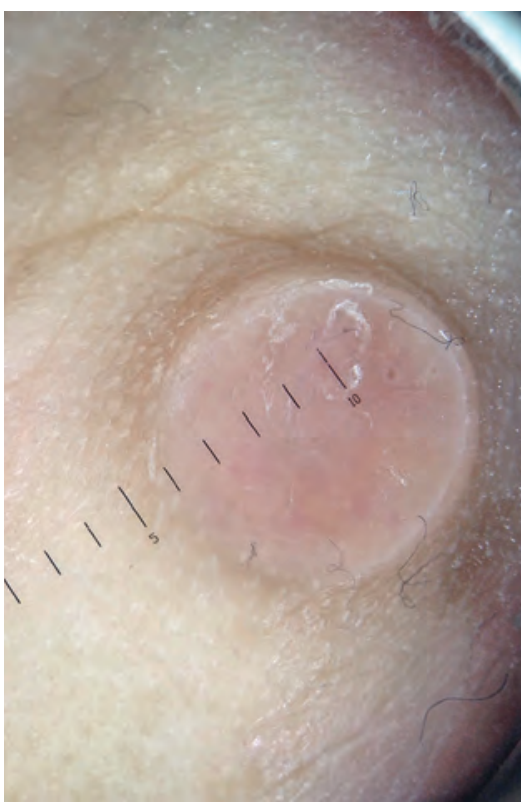

Figure 2: Dermoscopy: Pink structureless lesion with superficial scale. Note that no vascular structures are identifiable and the pigmented reticulum is absent

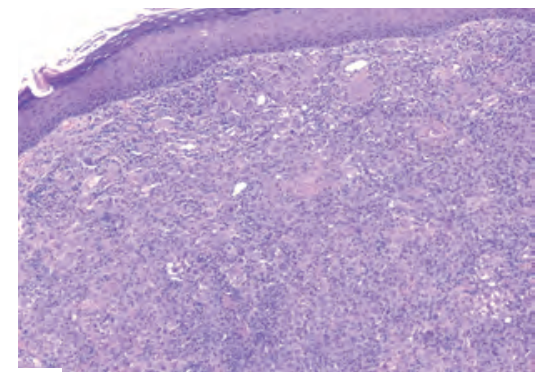

Figure 3: A - Nodular dermal area composed of large histiocytic cells and associated mononuclear infiltrate. The epidermis is unaltered (Hematoxylin \& eosin, x40); B) - Higher magnification shows large epithelioid histiocytes with multiple vacuolated nuclei and ground glass cytoplasm (Hematoxylin \& eosin, $\mathrm{x} 400$ )

\section{DISCUSSION}

Reticulohistiocytosis represents a group of uncommon non-Langerhans cell histiocytic proliferations affecting skin and soft tissues. There are two main types: solitary cutaneous reticulohistiocytoma (SCR), which is a benign cutaneous neoplasm, and multicentric reticulohistiocytosis (MR), presenting with multiple cutaneous lesions, destructive polyarthritis, and frequent involvement of internal organs. SCR, or solitary epithelioid histiocytoma, mostly affects young adults, with slight male predominance. The

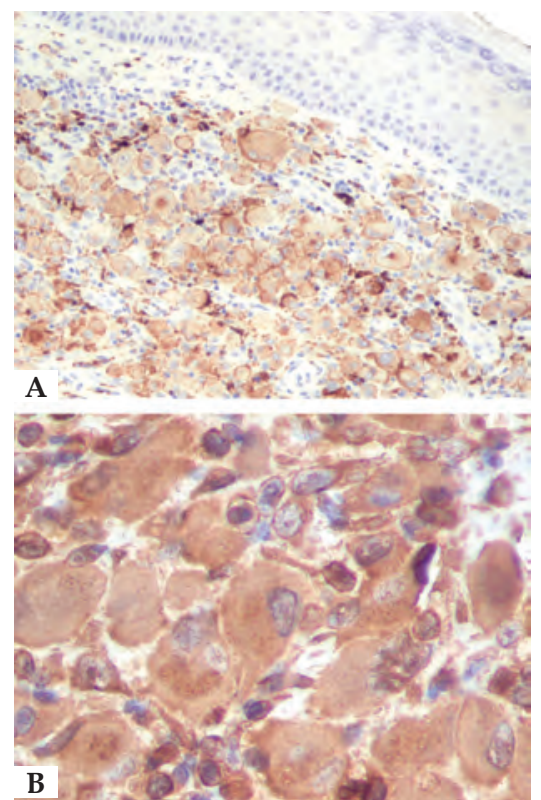

Figure 4: Immunohistochemical staining positive. A - CD68 (x100) and B - Vimentin $(x 400)$

largest reported series of 44 patients showed that trunk and lower extremities are the most frequently affected sites. Clinically, SCR manifests as a small well-circumscribed reddish-brown rapidly growing nodule on the skin or mucous membranes. ${ }^{1}$ Dermoscopy has been suggested as an auxiliary tool in the diagnosis of reticulohistiocytoma. To the present day, there are only five reports describing dermoscopic findings of SCR, and the dermoscopic presentation however varies among them. The dermoscopic features reported include a uniform central yellow area and the "setting sun" pattern, central white-grayish area, brown globules, and dots or white-pinkish streaks at the periphery of the lesion. The vascular structures are absent, apart from the latest report of a SCR with arborizing vessels at the periphery mimicking basal cell carcinoma. ${ }^{2,3}$

The histology of reticulohistiocytoma is characterized mainly by a dermal infiltrate of large uniform histiocytes and multinucleated giant cells with densely eosinophilic cytoplasm. Associated mixed lymphocytic, plasmacytic, eosinophilic and neutrophilic inflammatory infiltrate may also be present. The histiocytes of SCR express consistent positivity for CD68 and CD163 and show weak or negative immune staining for S-100 protein, MITF, CD1a, and XIIIa. ${ }^{1,4,5}$

Treatment involves surgical removal of the lesion. Even after an incomplete excision of the tumor, the recurrence of the SCR occurs infrequently. ${ }^{5}$ Unlike MR, SCR presents a benign course and is not associated with systemic disease. Our patient was healthy and presented with only one lesion, thus MR was excluded. Due to its uncharacteristic clinical presentation, SCR may mimic other benign lesions (Spitz nevus, xanthogranuloma, pyogenic granuloma, fibrolipoma), and importantly also malignant cutaneous neoplasms (amelanotic melanoma and histiocytic or epithelioid sarcoma), which should always be ruled out by skin biopsy. ${ }^{1,3}$ 
Abstract: Reticulohistiocytomas represent a group of benign histiocytic dermal proliferations, which occur either sporadically as solitary cutaneous nodules or, when multiple, in association with systemic disease. Due to its nonspecific clinical presentation, reticulohistiocytoma may mimic other benign or malignant skin neoplasms; therefore, in most cases, a biopsy is needed in order to establish the correct diagnosis. The histology is typically characterized by the presence of large histiocytes with abundant eosinophilic cytoplasm with immunohistochemical profile positive for CD68, CD163, and vimentin. The authors report the case of a patient with solitary reticulohistiocytoma with illustrative clinical, dermoscopic, and histologic features. Keywords: Dermoscopy; Histiocytes; Histiocytosis, non-Langerhans-cell; Skin neoplasms

\section{REFERENCES}

1. Miettinen M, Fetsch JF. Reticulohistiocytoma (solitary epithelioid histiocytoma): a clinicopathologic and immunohistochemical study of 44 cases. Am J Surg Pathol. 2006;30:521-8.

2. Guleç AT. Solitary reticulohistiocytoma with arborizing vessels: A new mimicker of basal cell carcinoma. J Am Acad Dermatol. 2016;74:e5-6.

3. de Oliveira FL, Nogueira LL, Chaves GM, Muniz MD, Timbó RP, Sasse MM, et al. A Unique Dermoscopy Pattern of Solitary Cutaneous Reticulohistiocytosis. Case Rep Dermatol Med. 2013;2013:674896.

4. Shibuya R, Tanizaki H, Kaku Y, Yonezawa M, Ryu Y, Otsuka A, et al. A Plaque-
Type Solitary Reticulohistiocytoma in a Two-Year-Old Boy. Case Rep Dermatol. 2015;7:7-9.

5. Cohen PR, Lee RA. Adult-onset reticulohistiocytoma presenting as a solitary asymptomatic red knee nodule: report and review of clinical presentations and immunohistochemistry staining features of reticulohistiocytosis. Dermatol Online J. 2014;20(3). pii: doj_21725.

\section{AUTHORS CONTRIBUTION}

Katarina Kieselova

(iD) ORCID 0000-0002-0064-7571

Approval of the final version of the manuscript; Elaboration and writing of the manuscript; Obtaining, analyzing and interpreting the data; Intellectual participation in propaedeutic and/or therapeutic conduct of cases studied; Critical review of the literature; Critical review of the manuscript

Felicidade Santiago ORCID 0000-0003-2402-4229

Approval of the final version of the manuscript; Intellectual participation in propaedeutic and/or therapeutic conduct of cases studied; Critical review of the literature; Critical review of the manuscript

\section{Cristina Amado \\ ORCID 0000-0002-5742-6569}

Approval of the final version of the manuscript; Obtaining, analyzing and interpreting the data; Intellectual participation in propaedeutic and/or therapeutic conduct of cases studied

Martinha Henrique

(iD) ORCID 0000-0001-7506-4971

Approval of the final version of the manuscript; Critical review of the literature; Critical review of the manuscript

How to cite this article: Kieselova K, Santiago F, Amado C, Henrique M. Case for diagnosis. Solitary violaceous nodule on the toe. An Bras Dermatol. 2018;93(4):595-7. 